\section{A vida nos olhos, 0 coração nas mãos: concepções e representações femininas do processo saúde-doença}

\section{Life in their eyes, heart in their hands:} conceptions and representations of women in the process of health and disease

\section{Glauce Dias}

Mestranda em ciência da nutrição glaucedias@yahoo.com.br

Sylvia do Carmo Castro Franceschini

Departamento de Nutrição e Saúde Sylvia@ufv.br

José Roberto Reis

Departamento de Administração robereis@ufv.br

Roberta Sena Reis

Graduanda de nutrição robertaseis@yahoo.com.br

\section{Rodrigo Siqueira-Batista}

Departamento de Nutrição e Saúde Universidade Federal de Viçosa

Av. Peter Henry Rolfs, s.n. - Campus Universitário 35570-000 Viçosa - MG - Brasil

Rosângela Minardi Mitre Cotta

Centro Federal de Educação Tecnológica de

Química de Nilópolis

Rua Álvaro Moreira, 108 Gleba A

25964-000 Teresópolis - RJ - Brasil
DIAS, Glauce; FRANCESCHINI, Sylvia do Carmo Castro; REIS, José Roberto; REIS, Roberta Sena; SIQUEIRA-BATISTA, Rodrigo; COTTA, Rosângela Minardi Mitre. A vida nos olhos, o coração nas mãos: concepções e representações femininas do processo saúde - doença. História, Ciências, Saúde Manguinhos, Rio de Janeiro, v.14, n.3, p.779-800, jul.-set. 2007.

A abordagem histórico-social das representações de saúde e doença das mães do município de Teixeiras (MG) visa compreender as condutas nessa esfera e o desenvolvimento de pesquisas em saúde coletiva. Construíram-se atrativos semânticos e indicadores para uma visão pluralista de saúde-doença. A busca da felicidade foi apresentada como um conceito de saúde pelas mães, retomando aspectos filosóficos aristotélicos e espinosistas, mas elas deram mais destaque à ausência da doença. $\mathrm{O}$ modelo assistencial hegemônico fornece ainda fortes referenciais para interpretar tais experiências. Como a condição cuidadora da mãe facilita a compreensão de outros fatores que afetam o processo saúde-doença, é possível planejar ações de saúde menos alienantes e mais libertárias

PALAVRAS-CHAVE: representações; processo saúde-doença; humanização da saúde.

DIAS, Glauce; FRANCESCHINI, Sylvia do Carmo Castro; REIS, José Roberto; REIS, Roberta Sena; SIQUEIRA-BATISTA, Rodrigo; COTTA, Rosângela Minardi Mitre. Life in their eyes, heart in their hands: conceptions and representations of women in the process of health and disease. História, Ciências, Saúde - Manguinhos, Rio de Janeiro, v.14, n.3, p.779-800, July-Sept. 2007.

This social and historical investigation into the ways the health and sickness of mothers from Teixeiras municipality, Minas Gerais state, was represented is designed to comprehend behaviors in this sphere and help develop research in collective health. The semantics and indicators of a pluralistic view of disease and health, were built up from the most holistic to the most biomedical, from the most relational to the most individual. The quest for happiness was presented as a health concept by the mothers, which recalls Aristotelian and Spinozian philosophical concepts, but they put greater emphasis on the absence of illness. The prevailing welfare model still supplies useful references for interpreting such experiences. As the mother's status as care-taker helps one glean an understanding of other factors that affect the process of health and disease, it becomes possible to plan healthcare initiatives that are less alienating and more libertarian.

KEYWORDS: representations; process of health and disease; humanization of health. 
* Este artigo é parte da dissertação Atenção à saúde da criança e da gestante pelo Programa de Saúde da Família no município de Teixeiras $M G$, financiada pelo $\mathrm{CNPq}-$ Processo $\mathrm{n}^{\mathrm{O}}$ 401905/05-5, ano 2006 - Departamento de Nutrição e Saúde da Universidade Federal de Viçosa.
$\mathrm{A}^{\mathrm{s}}$ s representações ${ }^{1}$ de saúde e doença foram sempre pautadas pela inter-relação entre os corpos dos seres humanos, as coisas e os demais seres que os cercam (Castiel, 1999). A história dessas representações, ao longo dos séculos, revela que nelas habitam elementos naturais e sobrenaturais desde tempos imemoriais, provocando os sentidos e impregnando a cultura, os espíritos, os valores e as crenças dos povos (Sevalho, 1993). De fato, Le Goff (1991, p.7) comenta: "a doença [e podemos acrescentar a saúde] pertence não só à história superficial dos progressos científicos e tecnológicos como também à história profunda dos saberes e das práticas ligadas às estruturas sociais, às instituições, às representações, às mentalidades".

Nesse âmbito, pode-se considerar como um dos marcos da história das concepções de saúde e doença no Ocidente a emergência da Escola de Medicina da Ilha de Cós, cujo expoente máximo foi Hipócrates (Frias, 2001; Siqueira-Batista, 2003a). Com os médicos hipocráticos, nasce uma concepção 'laicizada' do processo saúdedoença, que desconsidera a intervenção dos deuses, tratando o adoecimento como uma conseqüência da desarmonia dos constituintes da physis (natureza), assim expresso:

O corpo do homem é constituído por sangue, flegma, bile amarela e bile negra; estes fazem a natureza de seu corpo e através deles se sente dor ou se tem saúde. Ele goza de saúde perfeita quando esses elementos são devidamente proporcionais em composição, poder e volume e quando eles estão perfeitamente misturados, juntos. (Hippocrates, 1992, p.11, tradução nossa)

O homem, desse ponto de vista, necessita harmonia (equilíbrio) tanto intrinsecamente quanto em relação a seu ambiente, para que possa gozar de boa saúde (Siqueira-Batista, 2003b). É precisamente nessa tradição que se inscreve, em épocas mais recentes, a associação do processo saúde-doença a elementos relacionados com a qualidade de vida, vida saudável e estilo de vida. A Organização Mundial da Saúde (OMS) define qualidade de vida como a percepção pelo indivíduo de sua posição no contexto da cultura e do sistema de valores em que se insere e em relação aos seus objetivos, expectativas e preocupações (WHOQOL, 1995).

Dessa forma, o presente estudo volta-se para a representação da saúde como um espaço em que se refletem interações entre atores sociais e seu contexto de vida, seu grupo, instituições e outras instâncias (Gomes, Mendonça, 2003). Almeja discutir as interações com base naquilo que as pessoas representam como saúde e nas condições de sua inserção social, permitindo conhecer o conjunto de concepções - das mais holísticas às mais biomédicas, das mais relacionais às mais individuais.

A abordagem se inicia demarcando, segundo as representações, diferentes pontos de vista, assim como trazendo aspectos que per- 
mitam subsidiar os processos investigativos voltados para a temática em questão. Nossa preocupação maior é compor um quadro que não só traga a síntese do diálogo entre diferentes perspectivas, mas também indique, por meio de referências, princípios para aprofundar a discussão. Em seguida, apresentamos os aspectos principais da análise narrativa. Ela tanto dá acesso às representações construídas como também procura compreender o modo como são produzidas, atualizadas ou transformadas e, dessa forma, contribuir para o planejamento das ações de saúde local.

\section{Métodos}

Descrição espaço-temporal e população estudada

A pesquisa foi realizada, no período de novembro de 2005 a fevereiro de 2006, em Teixeiras (MG), na região da Zona da Mata. Segundo o último censo demográfico, realizado em 2000 pelo Instituto Brasileiro de Geografia e Estatística (IBGE, 2000), o município tem uma população de 11.149 habitantes - dos quais, 6.949 (62,33\%) distribuídos na zona urbana e 4.200 (37,67\%), na zona rural -, apresentando uma taxa de urbanização de $62,33 \%$ e uma média de crescimento anual de 1,23\% (PNUD, Ipea, FJP, 2000).

Fizeram parte do grupo de estudos 161 mães de crianças de até dois anos, residentes no município de Teixeiras (94,7\% das mães com esse perfil no município), que relataram suas concepções e representações de saúde.

A assistência em nível de atenção primária é realizada, por intermédio do Sistema Único de Saúde (SUS) local, em quatro Unidades de Saúde da Família localizadas no meio urbano, e o Programa de Saúde da Família (PSF) cobre $100 \%$ da população. A relação das mães que se encaixavam no perfil foi fornecida pelos Agentes Comunitários de Saúde (ACS), por meio do cadastro dos usuários.

Coleta de dados

O presente trabalho fundamentou-se na pesquisa qualitativa, utilizando a Técnica de Conteúdos proposta por Minayo (2000), que compreende as seguintes etapas: (1) pré-análise, (2) exploração do material, (3) tratamento dos resultados obtidos, e (4) interpretação. A escolha dessa estratégia de análise justifica-se porque possibilita a compreensão das pessoas levando em consideração seus 'fazeres' e 'dizeres', seus inter-relacionamentos, seus costumes e crenças e, sobretudo, suas atribuições de significado às próprias experiências.

Inicialmente, fez-se contato com o prefeito e a secretária de saúde do município. Em um segundo momento, realizou-se uma reunião com os agentes comunitários de saúde (ACS) e os coordena- 
dores das Unidades Básicas de Saúde (UBS). Apresentaram-se, então, o objetivo da pesquisa, os métodos de entrevista, a forma de divulgação dos resultados e de retorno à comunidade e ao PSF. Os dados foram coletados por meio de entrevista semi-estruturada, contendo o questionário perguntas abertas sobre o conceito de saúde e de vida saudável. Gravaram-se todas as entrevistas, o que facilitou a análise posterior.

Análise dos dados

Após interpretação global das respostas, passou-se à análise de conteúdo. Essa etapa envolveu a organização do material, de acordo com as unidades de contexto, e a elaboração de categorias gerais para obter um panorama abrangente do material analisado. Em outra etapa do trabalho, as categorias foram agrupadas, após leituras reelaboradas de forma mais sintética, e contrapostas às observações e aos estudos bibliográficos para direcionar as discussões e as conclusões sobre a representação social de saúde-doença.

Aspectos éticos

O trabalho foi aprovado pelo Comitê de Ética em Pesquisa da Universidade Federal de Viçosa (UFV), em consonância com o disposto na Resolução 196/96 do Conselho Nacional de Saúde.

\section{Resultados e discussões}

Caracterização da população estudada

Alguns indicadores quantitativos serão brevemente apresentados para se conhecer a situação econômica e social do grupo estudado. Das 161 mães entrevistadas, 31,7\% tinham idade compreendida na faixa etária de 26 a 30 anos, sendo a média de idade de $27+$ 6,1 anos (média + desvio padrão); 12,4\% eram adolescentes na faixa etária de 16 a 19 anos; e 9,9\% tinham mais de 35 anos. Em sua maioria eram donas de casa (76,5\%); outras ocupavam-se em trabalhos manuais como o de bordadeira e manicura; outras ainda eram domésticas, comerciantes e trabalhadoras rurais, que serviam de apoio para o parceiro nas épocas de colheita; e as poucas que possuíam ensino superior eram, em geral, professoras. Quanto à situação conjugal, identificou-se $65,2 \%$ de mulheres casadas, $21,7 \%$ vivendo em comunhão livre, e 10,6\% de solteiras.

Em relação à renda familiar - um fator determinante nas condições de vida -, a média de ganho era de $\mathrm{R} \$ 300,00$ (um salário mínimo na época do estudo). A maioria, $48,4 \%$, ganhava na faixa de meio a um salário mínimo, e $13 \%$ ganhavam até meio salário mínimo. Quanto à escolaridade, $61,5 \%$ das mães possuíam nível funda- 
mental incompleto ( $1^{\underline{a}}$ a $8^{a}$ série), e dessas, $46 \%$ possuíam apenas da $1^{\text {a }}$ à $4^{\underline{a}}$ série. Somente $16,1 \%$ das mulheres chegaram a concluir o ensino médio, e 3,1\% tinham formação superior.

Atrativos semânticos e indicadores da saúde

O conjunto de representações de saúde tende a condensar-se, em alguns casos, em uma série de termos, de expressões, de imagens que exercem uma função de 'atrativos semânticos', de modo que em torno de cada termo se situa um conjunto de palavras, de expressões-chave significativas das situações e concepções próprias de cada grupo, como é o caso das mães teixeirenses (Conde, Marinas, 1997). Esses atrativos semânticos retirados das falas das mães levamnos a articular esse conjunto como um sistema de indicadores das citadas noções e representações de saúde, descritas no Quadro 1.

Após análise e esquematização, podemos investigar as significações que são mais evidentes e representativas para esse grupo.

\section{Quadro I - Atrativos Semânticos e Indicadores de saúde conforme o relato das mães de crianças menores de dois anos do município de Teixeiras, MG (2005-2006).}

\begin{tabular}{|lll|}
\hline \multicolumn{2}{|c|}{ Saúde como: } \\
\hline Vida Saudável & Hábitos Saudáveis & $\begin{array}{l}\text { A usência de } \\
\text { Doença }\end{array}$ \\
\hline Felicidade & Determinantes e condicionantes & Biomédica \\
Conotações Positivas & Conotações oscilantes & Conotações negativas \\
Equilíbrio & Saúde como resultante & Enfermidade \\
$\begin{array}{l}\text { Vincula o psíquico, físico } \\
\text { e relações sociais }\end{array}$ & Vincula ao físico & Físico fragmentado \\
Promoção de saúde e & Prevenção de doenças & Cura \\
prevenção de doenças & & \\
\hline
\end{tabular}

\section{Vida saudável}

O conjunto de noções e experiências de vida saudável do citado coletivo constitui elemento-chave e representativo. São apresentadas questões peculiares que identificam a mulher-mãe por suas características mais expressivas como o cuidado, o trabalho e o feminino. Trata-se de abordar a vida saudável como uma existência de doação, de felicidade e de equilíbrio-harmonia - como na fórmula hipocrática acima descrita - traduzida no ser mãe, mulher e trabalhadora, a despeito da exclusão e da desvalorização que geram conformismo, acomodação e aceitação. Portanto, a vida saudável é apresentada, em seus aspectos relacionais, como projeto de felicidade, trabalho e equilíbrio. 
Vida saudável e aspectos relacionais

É interessante perceber como os discursos evidenciam um modo de vida que se articula nas dimensões relativas à pessoa (mãe) assim como nas dimensões familiares e sociais:

É o que tem de mais importante, é estar bem em todos os sentidos, com todos, meus filhos, meu marido, é cuidar deles e de mim. (134)

Harmonia no lar, depois vêm outras coisas, cuidar da alimentação. (9)

É a criança ficar espertinha, forte, desenvolver bem, estar bem, ah! ficar mais alegre, aí a gente também fica. (154)

Cabe destacar que os discursos produzidos por esse grupo marcam uma linha interpretativa da noção de vida saudável como um 'sujeito em relação', como o 'eu em relação', discussões presentes no estudo "Salud y la mujer" (Conde, Marinas, 1997), sobre as relações e perspectivas de vida saudável. Esse estudo sustenta que a identidade e o sentido do ser feminino se reforçam e mantêm uma coesão, por meio das práticas das relações humanas, centrados no objetivo de criação e cuidado nas relações afetivas. Dessa forma, a matriz essencial do feminino no modelo maternal constitui-se na conexão com as necessidades do outro, a disponibilidade para a resposta adequada e o cuidado continuado.

Como vimos, as mães teixeirenses - que são em sua maioria donas de casa $(76,4 \%)$ - estão muito centradas nas responsabilidades do lar, dos filhos e do parceiro: são elas que cuidam, se entregam e estão sempre dispostas ao e para o outro. Assim, ver o outro bem é ver-se bem, também. Esse aspecto típico do modo de ser materno e feminino, fortemente marcado nas representações das mulheres entrevistadas, está presente nas concepções de Boff:

no fundo, tudo passa pelo outro, pois sem o diálogo com o tu não nasce o verdadeiro eu, nem surge o nós que cria o espaço da convivência e da comunhão ... A relação com o outro suscita a responsabilidade. É o que significa a palavra responsabilidade, dar um responso, uma resposta ao outro. É o outro que faz emergir a ética em nós. Ele nos obriga a uma atitude, ou de acolhida ou de rejeição. (Boff, 24 nov. 2004)

Essa atitude de 'acolhida' e de 'cuidado' da mãe se revela em todas as representações desde a concepção negativa, ausência de doença, à concepção positiva de saúde, produção social. Os relatos demonstram uma concepção de saúde com base no olhar para a criança e para a família, ou seja, em que o sujeito se volta para suas relações. 
Estudos demonstram algumas conseqüências significativas do 'eu em relação' (Conde, Marinas, 1997; Conde, Conchas, 2000): adiamento e desconhecimento dos próprios desejos; autovalorização centrada de forma prevalente e exclusiva na necessidade de ter um ambiente ativo na criação e manutenção de relações amorosas; tendência a evitar, reprimir e ou inibir por completo tudo aquilo sentimentos, atitudes, atividades e ideais - que ameace a manutenção de relações.

O mais importante é que se reitera o fato de que são dadas às mulheres condições de se tornarem agentes ativos de mudança e de assumirem o lado positivo dessa atitude cuidadora, gerando um ambiente cooperativo e cálido, importante para as prementes transformações em uma sociedade marcada pela violência, bem como para intervenções no próprio campo da saúde (Ayres, 2004; Aleksandrowicz, 2003).

Vida saudável como expressão de felicidade

Outro elemento retratado pelo grupo é a felicidade como meta, como projeto de vida, aspecto em sintonia com as concepções éticas aristotélicas (Aristóteles, 1985) e espinosistas (Spinoza, 2003). A questão central da ética aristotélica é 'como atingir a eudaimonia', palavra grega que pode ser traduzida como felicidade (Pohlenz, 1962; Reale, 1999). Para o filósofo de Estagira, a eudaimonia só pode ser alcançada no bojo da realização humana, que depende do exercício de determinadas faculdades, segundo as quais a vida se define (Barnes, 2001).

Baruch de Espinosa (1632-1677) retoma o legado de Aristóteles (Moreau, 1982; Scruton, 2001), tanto na metafísica - conceito de substância - quanto na ética - conceito de felicidade-, na medida em que sua filosofia busca o modo pelo qual se pode conhecer o mundo, agir e encontrar nele a felicidade (Scruton, 2001; Aleksandrowicz, 2007). De fato, o pensador holandês compreende a felicidade como uma expressão amorosa, de pertença produtiva a Deus, ao mundo e ao humano, que não se confunde com uma experiência mística, mas é uma experiência intelectual da potência criadora que se expressa nas paixões decorrentes da compreensão do Bem comum (Ayres, 2005): "A felicidade não éo prêmio da virtude, mas a própria virtude, e não gozamos dela por refrearmos as paixões, mas ao contrário, gozamos dela por podermos refrear as paixões" (Spinoza, 2003).

Dessa forma, vejamos como as mães relatam suas concepções de vida saudável, atreladas à idéia de felicidade:

É ser uma pessoa mais feliz, quando não tem saúde tá triste, é fazer coisas que dá prazer, é ter responsabilidade. (151)

Sempre em primeiro lugar, felicidade, ter muita felicidade, é o que a gente quer. (84) 
É ver uma criança feliz, brincando, poder ser, estar feliz sempre até crescer. (27)

É estar feliz, tem dia que a gente tá nervosa, mas é buscar ser feliz até quando as coisa tão difícil, é ser e estar feliz. (26)

Ser feliz, de bem com a vida, de bem com tudo, às vezes não tem uma doença e não está com saúde. (105)

É a pessoa que vive sempre alegre, que se cuida, que ajuda uma a outra, que alimenta bem. (31)

Ser feliz. A gente gostar da gente mesmo, do meu filho. [Mãe espancada no dia anterior pelo marido.] (96)

Os relatos chamam a atenção para aspectos, tanto coletivos como individuais, que reiteram a concepção teleológica de felicidade, caracterizando-a como um fim a ser alcançado, algo bastante semelhante ao ideário helênico - aristotélico - da vida prática (Aristóteles, 1985). Como a vida é intrinsecamente determinada pelo desejo de seguir, é o aumento da realização de todas as suas potencialidades que provoca a procura de uma existência mais significativa (Aleksandrowicz, 2003), ou seja, não querer viver por viver. Portanto, essa noção de felicidade nos remete a uma experiência valorada positivamente que, freqüentemente, independe de um estado de completo bem-estar ou de perfeita normalidade morfofuncional, ausência de doença (Ayres, 2004; Waldow, 2004), já que, como bem demonstra Aristóteles, trata-se de realização e não de um estado de espírito - ou de corpo-alma momentâneo.

Apesar da 'modéstia' nas representações das mamães, essas concepções de saúde - entendidas como felicidade - vêm tomando corpo no que tange à 'oportunidade para se alcançar um estado de felicidade...' e buscar uma qualidade da existência para além da sobrevivência (Nutbeam,1996, citado em Aleksandrowicz, 2003, p.68). Isso é o que parece haver de mais novo nas recentes propostas de humanização dos programas do SUS.

A humanização da saúde aparece como intervenção na lógica biomédica de percepção do sujeito e acaba por questionar paradigmas que sustentam essa forma de ver o mundo, a qual exclui o sujeito da co-responsabilidade em seu processo de cura, colocando o profissional como possuidor de uma verdade inquestionável (Reis, Marazina, Gallo, 2004; Santos, 2005). Dessa forma, afirma que práticas do processo saúde-doença, longe de se reduzirem a uma evidência orgânica e objetiva, estão intimamente relacionadas com as características de cada contexto sociocultural e também com a experiência subjetiva de cada pessoa (Castiel, 1999; Carvalho, 2005; Cotta et al., 2006; Yépez, Morais, 2004). 
Vida saudável como equilíbrio e trabalho

Tudo indica que a progressiva focalização das mães na própria experiência de seu corpo, na sua história pessoal e no seu ambiente, vem associada a características mais básicas e elementares de seu cotidiano. Podemos perceber que dois aspectos emergem do contexto e da realidade delas: o trabalho e o equilíbrio.

O primeiro e mais importante aspecto dimensionado é a disposição para o trabalho:

É a disposição para fazer as coisas, não tem ninguém pra fazer pra gente, marido tá trabalhando. (97)

Se sentir bem disposto para o trabalho, para o lazer. (40)

Ser uma pessoa boa, esportiva e o mais importante estar bem para trabalhar, fazer de tudo. (78)

Estar sempre de bem com a vida e poder trabalhar. (91)

Base de tudo, disposição para o trabalho. (1)

Trabalho expresso não só no espaço público, mas, especialmente, no espaço privado, doméstico. Essa contribuição invisível (trabalho não remunerado) das mulheres na forma de labor doméstico, mantém a vida em unidades familiares para a classe trabalhadora e garante a sobrevivência das instituições casamento e família, pois enquanto seus parceiros trabalham na lavoura, elas cuidam da casa e a limpam, fazem comida, cuidam dos menores e, ainda, auxiliam os maridos em épocas de colheita. Ademais, as mulheres que trabalham no espaço público, além da incorporação do trabalho assalariado, mantêm suas atividades domésticas (ou seja, não há a contrapartida de redistribuição do trabalho no lar).

Por isso, fazendo parte do cotidiano dessas mães trabalhadoras - ainda que, tantas vezes, tão pouco valorizadas - o labor é tão importante, constituindo elemento extremamente significativo no processo de formação de sua consciência, em concordância com o pensamento hegeliano, tal qual formulado na Fenomenologia do espírito (Hegel, 1992).

Essa disposição se deve não só à ausência de doença e de preocupações, mas, principalmente, a fatores determinantes como alimentação, cuidados profiláticos e valorização do que faz e do que é - mãe, trabalhadora, mulher.

É a pessoa alimentar bem, dormir bem, ter coragem para trabalhar. (14)

Poder trabalhar, para isso não sentir nada, dor, não ter que ficar tomando remédio. (24)

Não tá doente pra poder trabalhar. (55)

É não tá triste, fazer as coisa, trabalhar, mas ter recurso pra isso, eles não valorizam a gente, mas precisa trabalhar, né? (151)

Disposição pra acordar cedo e trabalhar, gosto quando ele chega e fala que tá bom o que eu fiz. (3) 
O fato de a agricultura familiar no município constituir um expressivo campo de trabalho permite entender que a inserção produtiva dos chefes de família, assim como da própria mulher que ajuda o parceiro e convive com essa realidade, submete os sujeitos a um intenso uso do corpo, que torna de grande importância a manutenção da saúde.

O 'equilíbrio' como noção de saúde aparece nas falas das mães como reflexo da inserção nos afazeres e cuidados diários, os quais trazem preocupações e responsabilidades que exigem moderação, ordem, tranqüilidade.

É ter tranqüilidade na vida, sem preocupações. (11)

Viver bem, tá com uma vida tranqüila, sentir bem com o que tem. (75)

Ser equilibrada na alimentação, no consumo, na vida. (78)

Não ficar com desespero, mas ser tranqüila para resolver as coisas. (48)

Esse aspecto é principalmente citado pelas mães da zona urbana, que conseqüentemente já possuem uma vida mais agitada. Sobressai, igualmente, em conexão com o equilíbrio-harmonia, que a tranqüilidade é um dos pontos significativos no horizonte da saúde.

Vida saudável: visão global da saúde

A concepção mais global de saúde, apesar de pouco expressiva, determina uma maior interação com o espaço social. A perspectiva das entrevistadas nesse indicador vem ao encontro de uma visão de Produção Social da Saúde e do Modelo Ideal de Saúde proposto pela OMS no ano de 1998, no movimento denominado Promoção da Saúde, que visa à superação da conhecida idealização do completo bem-estar físico e mental. Aproxima-se, também, do modelo funcionalista de Christopher Boorse (1975), cujo critério é a ausência de doença. O Modelo Ideal de Saúde supõe que ela é determinada e condicionada por vários fatores de ordem social, física, intelectual, espiritual e emocional, que estão inter-relacionados de modo a permitir o equilíbrio (como em Hipócrates) e o alcance de uma vida feliz (como em Aristóteles e Espinosa). Já o modelo da Produção Social da Saúde afirma que a condição ou estado de saúde advém das relações que se estabelecem no meio social, político, econômico e cultural (Mendes, 1996).

É tudo, higiene, alimentação, até educação, estado de espírito, se estou bem consigo levar a vida, é situação financeira, se não tenho dinheiro como vou comprá comida, remédio? (98)

Prioridade, educação lazer, não é só remédio, doença, são outras coisas também que a gente precisa pra ficá bem. (103) 
É a pessoa ficar de bem com tudo no físico, mental, com os outros, se alimentar bem, não adoecer com tanta freqüência. (112) Estar bem tanto na forma física, como emocional, espiritual, como um todo. (157)

É se relacionar bem, dentro de casa, com as pessoas, ter um trabalho digno pra colocar comida dentro de casa, paz, a violência tá muito grande ultimamente. (2)

Estar bem fisicamente em tudo, no trabalho, no dia-a-dia com a família. (21)

É de se destacar que há um pensamento coletivo, uma dimensão mais social, uma percepção não só física do corpo, mas a visão de um todo (e não de partes fragmentadas), que evoca os referenciais do pensamento sistêmico (Vasconcelos, 2003). Ademais, é possível recuperar a discussão em torno da saúde como desdobramento do debate mais amplo sobre a vida, no qual se vem compreendendo que os seres vivos são aqueles capazes de se auto-organizar (Atlan, 1992) ou de se organizar de forma autopoiética (Maturana, Varela, 1984), ou seja, produzirem-se continuamente a si mesmos, de acordo com uma íntima interação com o exterior (ambiente). Diante disso, uma concepção sistêmica - que enfatiza a integração dos determinantes que se somam de um ponto de vista mais global, mais holístico, mais dinâmico - revela-se muito mais fecunda para a compreensão do processo saúde-doença.

Segundo estudo que realizou um órgão sanitário espanhol - a Consejería de Sanidad y Servicios Sociales de Madrid (España, 1994) -, as mães dotadas de um discurso global-coletivo sentem-se responsáveis pela saúde da família em seu conjunto, já as que expressam uma noção mais individualista e fragmentada delegam tal responsabilidade às instituições sanitárias, especialmente ao médico.

As mães que têm um olhar mais ampliado para a saúde podem vir a atuar como agentes de transformação, fomentando a participação da comunidade assim como de outros setores na discussão de problemas sanitários, transpondo, dessa forma, as barreiras das instituições e dos serviços assistenciais.

\section{Hábitos saudáveis}

A noção de hábitos saudáveis constitui outro indicador de nosso estudo. Nas entrevistas, essa noção aparece estreitamente associada à prevenção de enfermidades e à promoção da saúde. Essas lídimas conexão e relação revelam-se tanto na concepção de vida salutar e equilibrada, quanto no sentido mais biomédico da prevenção para evitar a doença.

No caso das mães teixeirenses, verifica-se que os hábitos saudáveis formam parte importante no processo de cuidado das crianças e da família. 
Quero ver ele forte, espertinho, daí tem que cuidar desde cedo. (8) Eu dou o leite materno pra isso, pra ele comer de tudo mais tarde. (110)

Deve cuidar, é o mais importante, alimentar, cuidar dos dentes, procurar coisas saudáveis. (159)

É cuidado, pra ter saúde é preciso cuidá se alimentá bem. (144)

Perante uma lista de recomendações sanitárias que vão da perspectiva epidemiológica (como as contra-indicações relacionadas ao fumo e à bebida alcoólica) até a nutricional (como a valorização de uma alimentação saudável - Siqueira-Batista, 1995), as mães indicaram que orientam os filhos e a própria vida segundo hábitos salutares adquiridos pela experiência bem como por influência de sua cultura, da mídia e do próprio sistema de saúde. Tais hábitos referem-se a alimentação, higiene, atividade física, fumo e álcool.

\section{Alimentação}

A alimentação, neste caso, é uma questão-chave. A experiência, a cultura, as informações dos serviços de saúde e a própria mídia ensinam os benefícios de uma boa alimentação e os prejuízos e males de uma refeição pouco equilibrada. Para as entrevistadas trata-se de um componente essencial. Nesse sentido, o 'comer bem' e o 'comer comidas fortes' aparecem em um discurso vinculado sempre a exemplos paradigmáticos de uma boa saúde, que revela um olhar especialmente voltado para a família.

É ter cuidado com a alimentação, somos o que comemos. (76)

Comer coisas fortes para não adoecer, suco de couve de vez em quando, canja de galinha, verdura, comer de tudo. (61)

Alimentar bem, procurar coisas que tenham vitamina pros meninos crescer bem e a gente ficar forte também. (68)

Esses resultados reforçam achados de Loyola (1984), Minayo (1988) e Abreu (Abreu, Pordeus, Modena, 2005). Os autores mostram que a representação da saúde está intimamente ligada à idéia de força. Força que será utilizada no trabalho e que o alimento mantém e estimula. Para essas mães que precisam trabalhar e cuidar, a força e a disposição para o trabalho são de grande importância.

É interessante perceber, também, como a alimentação vem atrelada a condicionantes como dormir bem, brincar, e outros aspectos relacionados à prevenção.

É poder se alimentar bem, dormir bem, estar em dia com as vacinas. (70)

Alimentar bem, dormir bem e brincar. (56)

Quanto ao aleitamento materno - principal e exclusiva forma de alimentação infantil até seis meses de idade e preconizada pela 
OMS até dois anos -, as entrevistadas, em sua maioria, estendem essa fase por mais de seis meses, demonstrando que estão aderindo às recomendações e, ao mesmo tempo, assumindo seu papel de cuidadoras. No entanto, em geral, o leite não é oferecido de forma exclusiva até os seis meses de idade, e em alguns casos, apenas complementa a alimentação. Diante disso, as mães revelam suas dificuldades e argumentam:

A dor no bico atrapalha muito dar o peito. (13)

Não dá, preciso trabalhar, a criança se apega muito. (5)

É muito difícil para tirar a criança do peito, prefiro acostumar desde cedo a comer outras coisas. (28)

Não dei leite, estou dando chuquinha de NAN. Estou achando que não tá desenvolvendo direito, a médica liberou. (16)

Não saía nada. Saía uma quantidade que não valia de nada. Aí liguei na rua e comprei NAN. (117)

Meu leite não dava, o menino chorava muito, daí dei leite de vaca mesmo, não tenho condições de comprar o que a médica pediu. (51)

A análise desses relatos evidencia que a falta de persistência na introdução e continuidade da amamentação - gerada por um despreparo das mães jovens, pela preocupação com a criança que chora e também pela falta de habilidade de alguns profissionais que criam alternativas 'mais fáceis' -, bem como as dificuldades enfrentadas em virtude da introdução da mulher no mercado de trabalho e da ausência de leis que preservem o direito de aleitamento, impedem que os benefícios da amamentação interfiram de forma positiva na vida da criança e da mãe.

Além disso, como a maioria das entrevistadas não possui uma renda favorável à compra dos produtos recomendáveis, mas tem fácil acesso ao leite de vaca, que é distribuído por carroceiros, o consumo desse alimento in natura por crianças menores de seis meses é muito alto. Tal substituição pode levar a quadros de intolerância gastrintestinal e de alergias, além de não oferecer componentes essenciais e específicos que somente o leite materno possui (Souza, Almeida, 2004).

Apesar disso, as mães consideram importante a amamentação, que proporciona uma boa condição de saúde e desenvolvimento às crianças. Em contrapartida, não percebem os benefícios à sua própria saúde, como o melhor restabelecimento pós-parto e a prevenção do câncer de mama (Nakano, 2003). A amamentação é entendida essencialmente como alimento, afeto e proteção necessários à saúde da criança, como verificado em seus relatos:

O leite é importante pro neném, tem muita vitamina, vai ajudá ele crescer com saúde. (24)

Com certeza é bom, é sonho de toda mãe de amamentar no peito, penso que é o melhor pra eles. (10) 
O neném sente mais segurança pertinho da mãe e ele acaba crescendo com mais saúde, mais forte. (13)

Higiene

A higiene foi citada esporadicamente. Apareceram preocupações relacionadas ao asseio do corpo e do ambiente. Nesse aspecto, foram lembrados recursos que auxiliam no processo de limpeza.

Ter cuidado com o corpo, ter uma boa alimentação, ter filtro, dar banho na criança, mesmo a gente sendo pobre, é preciso cuidar. (10)

Deve cuidar dela, alimentar e cuidar dos dentes, escovar, cuidar da unha, ficar limpinha. (159)

Ter higiene, cuidar da casa direitinho, deixá limpinha pra todo mundo ficar com saúde. (80)

Segundo Duarte, citado por Víctora (2000), entre os membros da classe trabalhadora o corpo é pensado como uma realidade físico-moral. Para esse grupo, ele desempenha um papel ativo na construção da pessoa e da identidade social. Sendo assim, preocupações relacionadas com uma boa alimentação e higiene corporal expressam o valor e a necessidade de cuidados que garantam a prevenção de doenças e a manutenção do trabalho.

Atividade física, fumo e álcool

Questões relativas à atividade física, assim como ao fumo e ao álcool, incorporaram-se ao discurso das mães por intermédio da atuação dos profissionais de saúde e das informações transmitidas pelos meios de comunicação.

Não obstante, é importante destacar que o exercício corporal em academias, assim como caminhadas e práticas esportivas, não pertencem ao contexto sociocultural das entrevistadas, o qual envolve atividades físicas voltadas para o trabalho doméstico e do campo:

Eles falam que é importante fazer caminhada, exercício físico pra ter saúde, não ficar doente. (113)

É praticar esportes, se alimentar bem, isto tudo de bom que eles falam por aí. (4)

É fazer atividade física, brincar, está alegre. (103)

Nesse sentido, salienta-se que os relatos não traduzem experiências de atividades físicas tais como práticas esportivas, demonstrando apenas um aspecto representacional - 'eles falam'.

Já o controle do fumo e do alcoolismo é citado como um determinante a mais na prevenção da doença: 
Alimentar bem, parar de fumar também é importante, tomar bastante líquido e mais para não ficar doente e saudável. (115)

Comer coisas que fazem bem, que dá saúde, o álcool estraga com a vida da pessoa. (7)

Não fumar, não beber, atividade física, isso tudo ajuda a gente a ficar bem. (112)

\section{Ausência de doença}

Há que se destacar que a concepção da saúde como ausência de doença aparece neste estudo como uma dimensão de destaque entre as entrevistadas, relacionada à utilização da tecnologia médica e também à ausência de dor e de enfermidade. Apresentamos aqui uma visão 'medicalocêntrica', biológica, fragmentada e individualista (Abreu, Pordeus, Modena, 2005).

Esse fato mostra que a população se apropria do modelo sanitário hegemônico, perante o qual o ser humano é considerado uma máquina, e a doença, um mau funcionamento do organismo. $\mathrm{O}$ papel do médico, segundo essa lógica mecanicista, consiste em intervir física ou quimicamente para consertar um defeito de funcionamento do mecanismo (Capra, 1989). A visão popular, portanto, sofre influência das práticas dos profissionais, dos gestores, do sistema e das políticas de saúde.

Estar sem alguma doença, sem dor. (102)

Não sentir dor nenhuma, nem outro tipo de doença. (17)

Não ficar internada, passando mal. (73)

Não ter problema nenhum, pressão alta, câncer, problemas no coração. (148)

Ter um lugar para ser atendido, um hospital. (72)

É bom não estar doente. (150)

Algumas mulheres enfatizam em seus relatos uma espécie de ânsia por autonomia:

Não ter que tomar remédio controlado, ir ao médico sempre. (110)

Sem dependência de remédio, de médico, ficar acamado. (69)

Ficar de cama, vegetando, depois que adoece nunca é o mesmo. (57)

Já outras mães apontam a doença como parte de sua realidade e experiência:

Não sentir nada, não ter dificuldade de nada. A cabeça da minha filha dói muito, ela não é uma pessoa saudável. (74)

Eu tenho pressão alta, quer dizer que não tenho saúde boa. (141)

Não ter problema nenhum, meu filho mais velho deu um trabalho, teve bronquite. (92) 
Embora a experiência da doença, de aflição e dor, interfira muito na vida da sociedade, da família e da pessoa, e não possa ser, portanto, negligenciada, em nosso caso ela se refere, basicamente, à forma como as pessoas e os grupos sociais assumem a condição da doença ou nela se situam. Ter uma vida saudável não significa estar livre de tal condição, mas sim do significado que se dá a ela.

Não queremos aqui simplesmente apresentar as representações ou a experiência da doença, mas esclarecer que por força do cuidado materno, mesmo a prevenção e até a ausência da doença adquirem um significado importante, que influencia o modo de vida individual e social. O equívoco reside em considerar que o processo de adoecimento diga respeito somente a questões biológicas, esquecendo que existem outros fatores que também interferem, e que mesmo em presença de determinada patologia pode-se viver bem, com saúde.

Tal processo não pode, ainda nos dias de hoje, ser caracterizado apenas segundo seus aspectos biológicos, devendo, outrossim, ser entendido como um fenômeno intimamente relacionado com as características da sociedade na qual o doente é um ator social. Existe, assim, uma ordem de significações culturais nos fenômenos de adoecimento humano (Minayo, 1993).

Consideramos, ainda, a forma por meio da qual essa visão 'negativa' de saúde busca promover a ausência de doença: valendo-se de mais medicamentos, médicos, hospitais, exames, ambulâncias e consultas, gerando um mercado em que qualquer um pode 'comprar' saúde. Jogar esse jogo reforça as condições em que ele é praticado (Cotta, Mendes, Muniz, 1998).

\section{Espaços de saúde}

Após a investigação descrita, podemos indicar como as diferentes concepções e representações da saúde podem abordar e analisar um espaço global, mais ou menos descontínuo, em que coexistem quatro subespaços que representam as principais características discursivas das mães, como verificado em outros estudos (Conde et al., 2002) Nesses subespaços se produziram e condensaram diferentes noções parciais, tal como representamos na Figura 1.

Por meio da representação dessa figura, não se pretende elaborar uma simples quantificação, mas sim um dimensionamento desses espaços apresentados pelas mães. No eixo y apresentamos, na parte superior, a 'instituição' e, na parte inferior, o 'social' - tendo em vista que os problemas de saúde são ainda solucionados numa perspectiva institucional, resultando em pouca participação e intervenção da própria sociedade; como se existisse uma elite dominante, com poder sobre o processo de cura e de alternativas para prevenir doença e promover saúde. 
Figura I. Subespaços construídos a partir das representações sociais de saúde das mães do município de Teixeiras, MG (2005-2006)

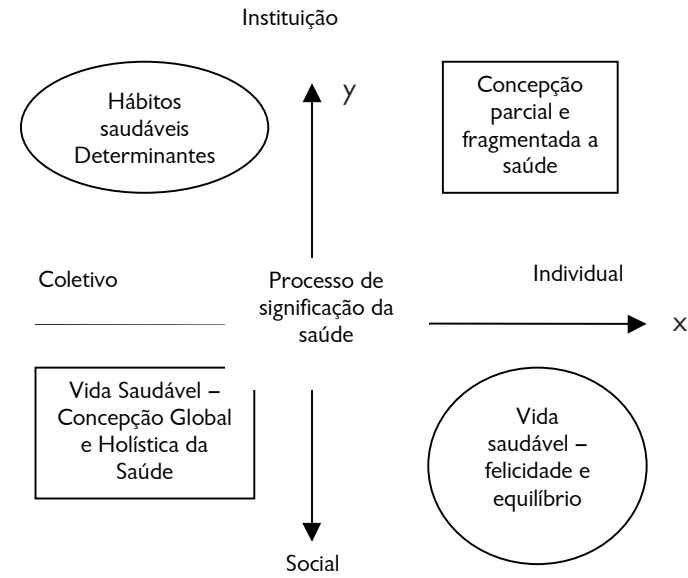

Adaptado e modificado de Conde \& Concha, 2000

No eixo $x$, apresentamos o âmbito de percepção da mãe, coletivo ou individual. Verificamos que o olhar materno ainda é muito individualista, principalmente no que se refere ao aspecto de saúde como ausência de doença. A dimensão de vida saudável, apesar de conceituada ainda numa perspectiva individualista, não é garantida por uma via institucional e sim, social, principalmente relacionada à família.

Os quadrantes retratam o dimensionamento desses espaços. A representação das entrevistadas encontra-se ainda marcada por uma visão de saúde parcial e fragmentada de forma individualista e biomédica (quadrante I - positivo), que encontra soluções para seus problemas em instituições hospitalares, nos postos de assistência e no sistema de saúde de forma geral.

Os hábitos saudáveis, apesar de se encontrarem no quadrante II, oscilam entre uma perspectiva coletiva e individual - por isso a seta apontada para o lado individual, mas cercada por soluções institucionais, aqui representadas pelo Estado. Este deveria garantir condições de trabalho, renda, educação e alimentação, entre outros direitos que determinam e condicionam o estado de saúde, conforme expresso na Constituição brasileira de 1988 (Brasil, 2000).

A concepção 'global e holística' retrata uma noção mais coletiva e social, a saúde vista como produção social (Mendes, 1996). Existem inúmeros fatores não-biológicos que alteram o equilíbrio saúdedoença, como aspectos psicológicos, emocionais, relacionais, espirituais e sociais. Esse processo é influenciado por questões econômicas, políticas e sociais, cujas soluções estão no envolvimento da sociedade com a busca de transformações e de soluções para os problemas vigentes como má distribuição de renda, baixa escolaridade e desvalorização do trabalho rural, doméstico e feminino. No 
entanto, verifica-se que o aspecto 'produção social' está dimensionado no quadrante negativo, indicando uma representação das entrevistadas ainda pouco expressiva.

\section{Considerações finais}

As representações da saúde configuram aspectos individuais e coletivos que caracterizam as mães por uma atitude cuidadora. Nessa perspectiva, o cuidado materno sempre 'em relação à', é apresentado como busca de prevenção de doenças e de promoção da saúde de suas crianças, de seu cônjuge, de sua família e de si mesma.

O referencial de felicidade-eudaimonia apresenta uma característica de projeto, de busca de um fim por meio de autocontrole que segue uma perspectiva claramente teleológica. O trabalho garante a sobrevivência, e a mãe se dispõe sempre a conservar essa conquista. Em virtude disso, suas representações baseiam-se em determinantes da saúde tais como a alimentação, a qual assegura a força com que se manter nos trabalhos do dia-a-dia.

Já as experiências da doença, dor e aflição, assim como as influências de um sistema sanitário biomédico, determinam uma concepção de saúde como ausência de doença de forma expressiva. Isso influencia a perpetuação de programas, políticas e práticas baseados em uma visão sanitária fragmentada e superficial, calcados no conformismo, na falta de participação e de atuação da população nos processos de mudança e reforma.

Contudo, percebemos que, ainda assim, podem ser identificadas perspectivas e inferências que se inscrevem em uma visão mais holística, composta por dimensões sociais, espirituais e emocionais, que muito interferem no processo saúde-doença. São representações mais coletivas que precisam ganhar força para conferir as mudanças e transformações tão necessárias ao sistema sanitário.

$\mathrm{O}$ entendimento das representações peculiares às mães teixeirenses poderá levar a um planejamento de ações de saúde menos alienantes e mais libertárias. E interessante que haja uma superação do sistema biomédico, baseado prevalentemente nos conhecimentos bio-fisiológicos, os quais são ainda dominantes nas práticas de saúde. Essa superação é possível em virtude da condição cuidadora da mãe, que facilita a compreensão de outros fatores que afetam o processo saúde-doença. Apesar da baixa escolaridade revelada no perfil das entrevistadas, na medida em que o processo de adoecimento e de uma vida saudável faz parte de sua experiência, de suas vivências bem como de seu cotidiano, somos levados a crer no potencial de compreensão e inserção das mães nas práticas educativas. É justamente isso que os profissionais de saúde precisam entender, ou seja, que as usuárias dos serviços de assistência possuem saber - como já amplamente demonstrado na obra de Paulo 
Freire (2003) - e por isso precisam ser escutadas nas suas demandas de saúde, de modo que se sintam parte do processo de cuidado. Para tanto, é necessária a sensibilização desses profissionais de saúde.

Promover a saúde é fundamental, sob a condição de que tal práxis possa se estruturar em torno de uma base ética e política, reunindo valores fundados na hospitalidade e acolhida incondicionais do outro, como formulado por Leonardo Boff (2001) e Jacques Derrida (2003). A acolhida - expressão final da 'compaixão' - se instaura por meio do profundo respeito à biografia e à cultura do outro, bem como do reconhecimento de que ele alberga a vida nos olhos e o coração nas mãos. Ela permite consubstanciar as bases para o estabelecimento de uma aliança duradoura, premissa fundamental para construirmos, juntos, um sistema de saúde justo, eqüitativo e resolutivo, aspectos necessários à realização - aristotélica e espinosista - de uma existência mais feliz.

\section{NOTA}

1 'Representação' é um termo de origem medieval que pode significar imagem ou idéia. De acordo com Nicola Abbagnano (1970), Guilherme de Ockham divisa três significados principais: “Em primeiro lugar, designa-se com este termo aquilo por meio do qual se conhece algo; nesse sentido o conhecimento é representativo, e representar significa ser aquilo com que se conhece alguma coisa. Em segundo lugar, por representar entendese conhecer alguma coisa, após cujo conhecimento conhece-se outra coisa; nesse sentido, a imagem representa aquilo de que é imagem, no ato de lembrar. Em terceiro lugar, por representar entende-se causar o conhecimento do mesmo modo como o objeto causa o conhecimento ... No primeiro caso, [representação] é a idéia no sentido mais geral; no segundo é a imagem; no terceiro, é o próprio objeto" (p.821) De modo semelhante, para Descartes, nas Meditações metafísicas, estabeleceu-se a noção de idéia como 'quadro' ou 'imagem' da coisa. Com efeito, no presente artigo adota-se o sentido de idéia, tal qual o formulado por Ockham e Descartes. (Cf. Abbagnano, 1970).

\section{REFERÊNCIAS BIBLIOGRÁFICAS}

Abbagnano, Nicola 1970

Abreu, Mauro H. N. G.; Pordeus, Isabela A.; Modena, Celina M. 2005

Aleksandrowicz, Ana Maria Coutinho 2007

Aleksandrowicz, Ana Maria Coutinho 2003

Aristóteles 1985

Atlan, Henri 1992
Dicionário de filosofia.

São Paulo: Mestre Jev.

Representações sociais de saúde bucal entre mães no meio rural de Itaúna (MG) - 2002. Ciências \& Saúde Coletiva, v.10, n.1, p.245-56.

O paradigma da complexidade no século XXI: da filosofia e ética da biologia a uma evolução antropológica e psicoafetiva em curso. Tese (Doutorado) Escola Nacional de Saúde Pública/Fiocruz, Rio de Janeiro.

Complexidade e metodologia: um refinado retorno às fronteiras do conhecimento. In: Minayo, Maria Cecília de Souza; Deslandes, Suely Ferreira (Org.). Caminhos do pensamento: epistemologia e método. Rio de Janeiro: Fiocruz. p.49-79.

Ética a Nicômaco.

Brasília: Ed. UnB.

Entre o cristal e a fumaça: ensaio sobre a organização do ser vivo.

Rio de Janeiro: Jorge Zahar. 
Ayres, José Ricardo de C. $M$. 2005

Ayres, José Ricardo de Carvalho Mesquita 2004

Barnes, Jonathan 2001

Boff, Leonardo

25 nov. 2004

Boff, Leonardo 2001

Boorse, C. 1975

Brasil 2000

Capra, Fritjof 1989

Carvalho, Sérgio Resende 2005

Castiel, Luís David 1999

Conde, Fernando;

Concha, Gabriel 2002

Conde, Fernando; Marinas, José Miguel 1997

Cotta, Rosângela

Minardi M. et al. 2006

Cotta, Rosângela Minardi M.; Mendes, Fábio F.; Muniz, José Norberto 1998

Derrida, Jacques 2003

España 1994

Freire, Paulo 2003

Frias, Ivan Miranda 2001
Hermenêutica e humanização das práticas de saúde.

Ciência E Saúde Coletiva, Rio de Janeiro, v.10, n.3, p.549-560.

O cuidado, os modos de ser (do) humano e as práticas de saúde. Saúde e Sociedade, São Paulo, v.13, n.3, p.16-29.

Aristóteles.

São Paulo: Loyola.

O outro é tudo. JB on line, Colunas.

Disponível em: http://www.jbonline.terra.com.br/jb/papel/colunas/boff/ 2004/11/25/jorcolbof20041125001.html.

Princípio de compaixão e cuidado.

3.ed. Petrópolis: Vozes.

On the distinction between disease and illness.

Philosophy and Public Affairs, Princeton, v.5, p.49-68.

Constituição da República Federativa do Brasil.

São Paulo: Ed. Revista dos Tribunais.

O ponto de mutação: a ciência, a sociedade e a cultura emergente. São Paulo: Cultrix.

Saúde coletiva e promoção da saúde: sujeito e mudança.

São Paulo: Hucitec.

Histórias clínicas: categorias para o corpo que adoece. In: Vaitsman, J; Girardi, S. (Org.). A ciência e seus impasses: debates e tendências em filosofia, ciências sociais e saúde. Rio de Janeiro: Fiocruz. p.149-179.

La evolución de las representaciones sociales sobre la salud de las mujeres madrileñas - 1993-2000. Revista Española de Salud Pública, Madrid, n.76, p.493-507.

Las representaciones sociales sobre la salud de los mayores madrileños.

Madrid: Consejería de Sanidad y Servicios Madrileños. (Documento Técnico de Salud Pública, 50).

Organização do trabalho e perfil dos profissionais do Programa de Saúde da Família: um desafio na reestruturação da atenção básica em saúde. Epidemiologia e Serviços de Saúde, Brasília, v.15, n.3, p.7-18.

Descentralização das políticas públicas de saúde: do imaginário ao real. Viçosa: Universidade Federal de Viçosa.

Voyous.

Paris: Galilée.

Consejería de Sanidad y Servicios Sociales. Informe sobre la salud y la mujer en la Comunidad de Madrid. Madrid: Consejería de Sanidad y Servicios Sociales. (Documento Técnico de Salud Pública, n.32).

Pedagogia da autonomia: saberes necessários à prática educativa. São Paulo: Paz e Terra.

Platão, leitor de Hipócrates.

Londrina: Ed. UEL. 
Gomes, Romeu; Mendonça, Eduardo Alves 2003

Hegel, Georg W. F. 1992

Hippocrates 1992

IBGE 2000

Le Goff, Jacques 1991

Loyola, Maria Andréa 1984

Maturana, Humberto; Varela, Francisco J. 1984

Mendes, Eugênio Villaça 1996

Minayo, Maria Cecília de Souza 2000

Minayo, Maria Cecília de Souza 1993

Minayo, Maria Cecília de Souza 1988

Moreau, Pierre-François 1982

Nakano, Ana Márcia Spanó 2003

Nutbeam, D. 1996

Pohlenz, Max 1962

PNUD; Ipea; FJP 2000

Reale, Giovanni 1999

Reis, Alberto Olavo A.; Marazina, Isabel V.;

Gallo, Paulo R.
A representação e a experiência da doença: princípios para a pesquisa qualitativa em saúde. In: Minayo, Maria Cecília S.; Deslandes, Suely F. (Org.). Caminhos do pensamento: epistemologia e método. Rio de Janeiro: Ed. Fiocruz. p.109-132.

A fenomenologia do espírito.

Petrópolis: Vozes.

Nature of Man. English translation by W. H. S. Jones.

Cambridge (Mass.): Harvard University Press.

Instituto Brasileiro de Geografia e Estatística.

Censo demográfico. Brasília: IBGE.

Uma história dramática. In: Le Goff, Jacques (Org.).

As doenças têm história. Lisboa: Terramar.

Médicos e curandeiros: conflito social e saúde.

São Paulo: Difel.

El árbol del conocimiento.

Santiago: Behncke.

Uma agenda para a saúde.

São Paulo: Hucitec.

Pesquisa social: teoria, método e criatividade.

Petrópolis: Vozes.

O desafio do conhecimento: pesquisa qualitativa em saúde.

Rio de Janeiro: Hucitec; Abrasco.

Saúde doença: uma concepção popular da etiologia.

Cadernos de Saúde Pública, Rio de Janeiro, v.4, n.4, p.363-381.

Espinosa e o espinosismo.

Lisboa: Edições 70.

As vivências da amamentação para um grupo de mulheres: nos limites de ser 'o corpo para o filho' e de ser 'o corpo para si'. Cadernos de Saúde Pública, Rio de Janeiro, v.19, supl. 2, p.S355-363.

Glosario de la Promoción de la Salud. In: OPAS. Promoción de la Salud: una antologia. Publicación cientifica $n^{\circ} 557$.

L'uomo greco.

Firenze: La Nuova Italia.

Programa das Nações Unidas para o Desenvolvimento; Instituto de Pesquisa Econômica Aplicada; Fundação João Pinheiro. Atlas do Desenvolvimento Humano no Brasil. Índice de Desenvolvimento Humano Municipal. Brasília. Disponível em: www.ipea.gov.br. Acesso em: 10 ago. 2007.

História da filosofia antiga. v.1. São Paulo: Loyola.

A humanização na saúde como instância libertadora. Saúde e Sociedade, São Paulo, v.13, n.3, p.36-43. 
Santos, Silvio Silva 2005

Scruton, Roger 2001

Sevalho, Gil 1993

Siqueira-Batista, Rodrigo

$2003 a$

Siqueira-Batista, Rodrigo

$2003 b$

Siqueira-Batista, Rodrigo 1995

Souza, Luciana Maria B. da M.; Almeida, João

Aprígio G. 2004

Spinoza, Baruch 2003

Vasconcelos, Maria José E. de 2003

Víctora, Ceres Gomes 2000

Waldow, Vera Regina 2004

WHOQOL 1995

Yépez, Marta T.;

Morais, Normanda A. 2004
A integração do ciclo básico com o profissional no curso de graduação em Medicina: uma resistência exemplar. Teresópolis: Papel \& Virtual. (Coleção Feso).

Espinosa.

São Paulo: Loyola.

Uma abordagem histórica das representações sociais de saúde e doença. Cadernos de Saúde Pública, Rio de Janeiro, v.9, n.3, p.349-363.

Deuses e homens: mito, filosofia e medicina na Grécia antiga.

São Paulo: Landy.

O espírito helênico: o poeta, o filósofo e o médico na Grécia antiga. Revista Brasileira de Filosofia, São Pualo, v.52, n.212, p.465-484.

Nutrição e saúde: novas perspectivas.

Jornal Brasileiro de Medicina, Rio de Janeiro, v.69, p.136-144.

História da alimentação do lactente no Brasil: do leite fraco à biologia da excepcionalidade. 1.ed. Rio de Janeiro: Revinter.

Ética demonstrada à maneira dos geômetras.

São Paulo: Martin Claret.

Pensamento sistêmico: o novo paradigma da ciência.

Campinas: Papirus.

Corpo, saúde e doença na antropologia. In: Víctora, Ceres Gomes; Knauth, Daniela Riva; Hassen, Maria de Nazareth Agra. Pesquisa qualitativa em saúde: uma introdução ao tema.

Porto Alegre: Tomo Editorial.

O cuidado na saúde: as relações entre o eu, o outro e o cosmos.

Petrópolis: Vozes.

The World Health Organization Quality of Life Assessment (WHOQOL): position paper from the World Health Organization. Social Science and Medicine, Oxford, v.41, n.10, p.403-449.

Reivindicando a subjetividade dos usuários da rede básica de saúde: para uma humanização do atendimento. Cadernos de Saúde Pública, Rio de Janeiro, v.20, n.1, p.80-88.

Recebido para publicação em setembro de 2006. 